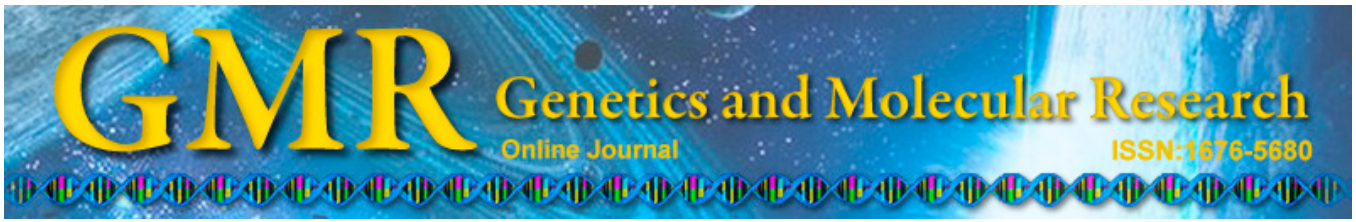

\title{
Molecular phylogeny of Colletotrichum (Sordariomycetes: Glomerellaceae) inferred from multiple gene sequences
}

\author{
H. Chen ${ }^{1,2}$, Y. Ma ${ }^{2}$, W.F. Zhang ${ }^{1}$, T. Ma ${ }^{1,2}$ and H.X. Wu ${ }^{1,2}$ \\ ${ }^{1}$ International Fungal Research \& Development Centre, \\ The Research Institute of Resource Insects, Chinese Academy of Forestry, \\ Bailongsi, Kunming, China \\ ${ }^{2}$ The Key Laboratory of Cultivating and Utilization of Resources, \\ Insects of State Forestry Administration, Kunming, China \\ Corresponding author: H.X. Wu \\ E-mail: haixiawu1983@126.com
}

Genet. Mol. Res. 14 (4): 13649-13662 (2015)

Received February 4, 2015

Accepted May 29, 2015

Published October 28, 2015

DOI http://dx.doi.org/10.4238/2015.October.28.27

\begin{abstract}
The genus Colletotrichum contains many important plant pathogens mainly distributed in tropical areas. Previous studies that utilized morphology or single genes have failed to resolve the phylogenetic relationships among the species. In this study, sequences of $\beta$-tubulin, 28S ribosomal DNA, and ITS region from nine species were analyzed separately and combined to establish a fast method to infer the phylogeny of Colletotrichum using maximum parsimony, maximum likelihood, and Bayesian inference methods. The tree topologies inferred from the combined data set received higher bootstrap and posterior probability support than those inferred from the individual data sets. Obtained phylogenies highly supported $C$. capsici as the earliest diverging lineage followed by $C$. nymphaeae. The remaining seven species clustered into two distinct clades. Clade 1 consists of two monophyletic subclades: C. circinans, C. trichellum, and C. caudatum form one subclade and three accessions of $C$. dematium form another
\end{abstract}


subclade. In Clade 2, C. incarnatum is in the basal-most clade. Three accessions of $C$. musae and C. caricae form a strongly supported clade indicating their close relationship. Spore shape analysis reveals an interesting evolutionary trend in the spore shape from acute- to obtuseended conidia and from curved to straight conidia in the sampled group of species. A quick and reliable way to infer the phylogeny of Colletotrichum based on combined DNA sequence data is presented in this paper.

Key words: Colletotrichum; $\beta$-tubulin; 28S rDNA; ITS; Molecular phylogeny

\section{INTRODUCTION}

The genus Colletotrichum belongs to the family Glomerellaceae (Sordariomycetes, Pezizomycotina, Ascomycota), which includes some of the most important plant pathogens worldwide, causes economically significant diseases in a wide range of hosts, including cereals, legumes, vegetables, perennial crops, and fruits (Moriwaki et al., 2002; Than et al., 2008; Manamgoda et al., 2013). Although mostly located in the tropics, it has a worldwide distribution (Wharton et al., 2001; Wharton and Diéguez-Uribeondo, 2004; Hyde et al., 2009; Prihastuti et al., 2010). Colletotrichum was first described by Tode in 1790 under the name Vermicularia but was later established as Colletotrichum by Corda in 1837 (Wharton et al., 2001; Moriwaki et al., 2002). Despite the original description and excellent illustrations provided by Corda, the genus has been described under several different names such as Blennorella and Gloeosporium. The names Colletotrichum and Blennorella were used interchangeably for several centuries for a range of species now accepted in the genus Colletotrichum (Sutton, 1992).

Traditionally, identification of Colletotrichum species has been based on morphological characters, such as size and shape of conidia and appressoria, existence of setae, the host origin, the teleomorph state, and cultural characteristics (von Arx, 1957; Smith and Black, 1990; Than et al., 2008; Peng et al., 2012, 2013). These characters were used to assign more than 750 Colletotrichum species to 11 species, with many taxa treated as synonyms of $C$. gloeosporioides and C. dematium (von Arx, 1957; Cai et al., 2009; Moura et al., 2014).

Many problems associated with the taxonomy of Colletotrichum species and their evolutionary relationships remain unresolved (Sreenivasaprasad and Talhinhas, 2005; Than et al., 2008). However, molecular biology provides new methods that can be utilized for species delimitation and defining of inter- and intraspecific relationships (Bruns et al., 1991; Lee et al., 2007). The most significant advances in phylogeny have been obtained from approaches based on the analysis of DNA and random amplified polymorphic DNA sequences as well as restriction fragment length polymorphism since the molecular data are not directly influenced by environmental factors (Welsh and McClelland, 1990; Williams et al., 1990; Faisal et al., 2013).

Most fungal phylogenetic studies utilized sequences from the ribosomal gene cluster, and the ribosomal DNA (rDNA) data of Colletotrichum species have been used to infer their phylogenetic relationships and for preliminarily identification (Sherriff et al., 1994; Cai et al., 2009). In particular, internal transcribed spacer (ITS) sequences have been proven to be useful in studying phylogenetic relationships of Colletotrichum species because of their comparative 
variability (Sherriff et al., 1994; Sreenivasaprasad et al., 1994, 1996; Moriwaki et al., 2002; Photita et al., 2005), and sequence analysis of $\beta$-tubulin gene was used to resolve phylogenetic relationships among Colletotrichum species complexes (Sreenivasaprasad and Talhinhas, 2005; Lee et al., 2007; Peng et al., 2013). Other gene fragments such as introns have also been utilized to evaluate the diversity of this genus (Guerber et al., 2003; Peres et al., 2008).

In the present paper, we assessed the interspecific relationships among nine species of Colletotrichum collected from different countries using sequences of $\beta$-tubulin and $28 \mathrm{~S}$ rDNA genes and the ITS region. The objectives of this research were: 1) to identify a quick method to infer the phylogenetic relationships in the genus; 2) to provide a reliable phylogenetic framework for nine species of Colletotrichum; and 3) to explore the implications of the molecular phylogeny and explore the evolutionary trend of the conidia in Colletotrichum, which provide a foundation for accurate diagnosis of pathogens and development of appropriate disease management.

\section{MATERIAL AND METHODS}

Different strains of nine species of Colletotrichum were collected from eight countries from different parts of the world (Table 1). Cultures were transferred aseptically to a potato dextrose agar (PDA) (Oxoid Ltd., Hampshire, UK) and incubated at $25^{\circ} \mathrm{C}$ (Than et al., 2008). Morphological characters of the cultures were examined under a compound microscope (Nikon 80i, Tokyo, Japan) and three subcultures from each isolate were prepared and used in subsequent analysis. Detailed information of the strains is shown in Table 1. All the isolates were subcultured and stored at room temperature at the International Fungal Research and Development Centre (Kunming, China).

\begin{tabular}{|c|c|c|c|c|}
\hline Name & Site & Identifier/Supplier & Host & Original code \\
\hline C. musae & Hong Kong, China & Hellen & Musa $\mathrm{sp}$ & 6,636 \\
\hline C. musae & Mae Taeng, Thailand & PoPo Than & Musa $\mathrm{sp}$ & 10,854 \\
\hline C. musae & Mae Taeng, Thailand & PoPo Than & Musa $\mathrm{sp}$ & 10,853 \\
\hline C. dematium & Wellington, New Zealand & J.M. Dingley & Crinum $\mathrm{sp}$ & 10,413 \\
\hline C. dematium & Auckland, New Zealand & J.M. Dingley & Aucuba $\mathrm{sp}$ & 10,400 \\
\hline C. dematium & Wellington, New Zealand & G. Laundon & Ranunculus repens $\mathrm{L}$. & 10,403 \\
\hline C. capsici & Sansai, Thailand & PoPo Than & Capsicum annuum & 10,858 \\
\hline C. circinans & Japan & NIAS & Allium cepa $\mathrm{L}$. & 10,375 \\
\hline C. caudatum & Queensland, Australia & BRIP & Aucuba sp & 10,448 \\
\hline C. nymphaeae & Netherlands, Herwijnen & H.A. van Kesteren & Nupharluteum & 10,655 \\
\hline C. incarnatum & East Africa, Boukoko & J. Nicot & Theobroma cacao & 10,732 \\
\hline C. caricae & Laboulaye, Argentina & CBS & Ficus carica & 10,742 \\
\hline C. trichellum & Japan & NIAS & Hedera helix & 10,378 \\
\hline
\end{tabular}

\section{DNA extraction}

Each isolate was grown on PDA for 7-10 days at $25^{\circ} \mathrm{C}$. Mycelium was scraped from the surface of the culture plate and used for DNA extraction. Total DNA was extracted using a Biospin Kit (Bioer Technology Co., Ltd., Hangzhou, China) according to the manufacturer protocol. DNA extracts were preserved at $-20^{\circ} \mathrm{C}$ until their use. 


\section{PCR and sequencing}

Amplification reactions were performed in a final volume of $50 \mu \mathrm{L}$ containing 25 ng DNA, $5 \mu \mathrm{L}$ 10X PCR buffer (Invitrogen, Carlsbad, CA, USA), $2.5 \mathrm{mM} \mathrm{MgCl}, 0.5 \mathrm{mM}$ dNTPs, $1 \mathrm{mM}$ of each primer, $1 \mathrm{U}$ Taq polymerase (Promega, Madison, WI, USA), and 29 $\mu \mathrm{L}$ ultrapure sterile water. The primers used for amplification and their sequences are listed in Table 2.

\begin{tabular}{|c|c|c|c|}
\hline Gene & Name & Primer sequence $\left(5^{\prime}-3^{\prime}\right)$ & Reference \\
\hline$\overline{\beta \text {-tubulin }}$ & $\begin{array}{l}\mathrm{T} 1 \\
\beta \mathrm{t} 2 \mathrm{~b}\end{array}$ & AACATGCGTGAGATTGTAAGT & O'Donnell and Cigelnik (1998) \\
\hline $28 \mathrm{~S}$ rDNA & $23032 / 1$ & TGAAAAGAACTTTGAAAAGAGA & Johnston and Jones (1997) \\
\hline & 28487 & CTTGGTCCGTGTTTCAAGACG & Johnston and Jones (1997) \\
\hline ITS & $\begin{array}{l}\text { ITS4 } \\
\end{array}$ & TCCTCCGCTTATTGATATGC & White et al. (1990) \\
\hline
\end{tabular}

DNA amplifications were carried out in a Bio-RAD MyCycler thermal cycler (Hercules, CA, USA) using different thermal regime for different regions. Amplification of $\beta$-tubulin sequences consisted of initial denaturation at $95^{\circ} \mathrm{C}$ for $4 \mathrm{~min}, 35$ cycles of denaturation at $64^{\circ} \mathrm{C}$ for $1 \mathrm{~min}$, annealing at $72^{\circ} \mathrm{C}$ for $2 \mathrm{~min}$, and extension at $72^{\circ} \mathrm{C}$ for $7 \mathrm{~min}$, and ended by cooling at $4^{\circ} \mathrm{C}$. Amplification cycles of $28 \mathrm{~S} \mathrm{rDNA}$ consisted of one cycle of initial denaturation at $94^{\circ} \mathrm{C}$ for $1 \mathrm{~min}, 35$ cycles of denaturation at $94^{\circ} \mathrm{C}$ for $1 \mathrm{~min}$, annealing at $55^{\circ} \mathrm{C}$ for $1 \mathrm{~min}$, and extension and $72^{\circ} \mathrm{C}$ for $1 \mathrm{~min}$, followed by a final step at $72^{\circ} \mathrm{C}$ for $3 \mathrm{~min}$. The ITS regions were amplified using the following cycle conditions: initial denaturation at $94^{\circ} \mathrm{C}$ for $5 \mathrm{~min}, 30$ cycles of denaturation at $94^{\circ} \mathrm{C}$ for $30 \mathrm{~s}$, annealing at $50^{\circ} \mathrm{C}$ for $30 \mathrm{~s}$, and extension at $72^{\circ} \mathrm{C}$ for $50 \mathrm{~s}$, followed by one cycle at $72^{\circ} \mathrm{C}$ of $7 \mathrm{~min}$. PCR products were purified with a QIAquick PCR purification Kit (Qiagen, Valencia, CA, USA). Sequencing of both strands was carried out on a CEQ2000XL automated sequencer (Beckman Coulter, Inc., Fullerton, CA, USA) with the same primers used for amplification. The resulting sequences were assembled using Bioedit version 7.0.5.3 (Hall, 1999) and deposited in GenBank (accession No. GQ369588GQ379701) (Table 3).

\section{Phylogenetic analyses}

Alignments of the individual data matrices were generated using similarity index calculated at the nucleotide level with ClustalW version 1.81 implemented in the Lasergene DNAstar software package (Thompson et al., 1997). The data sets were subjected to Bayesian phylogenetic inference, maximum likelihood (ML) analysis, and equal weights parsimony (MP) analyses to estimate the tree topology. For Bayesian inference, metropolis-coupled Markov Chain Monte Carlo simulations were carried out with MrBayes 3.1.2 (Huelsenbeck and Ronquist, 2001) to estimate the posterior probability distributions of the tree topologies. The best evolutionary models for ML analyses were generated using hierarchical likelihood ratio test estimated by Modeltest 3.06 (Posada and Crandall, 1998). Statistical support for each node was evaluated by bootstrap analysis (Felsenstein, 1985). Parsimony analyses were conducted in the PAUP 4.0b software (Swofford, 2001) using heuristic search algorithm (Hillis 
et al., 1996) with 1000 replicates of random-addition-sequence (Wu et al., 2011, 2014). The resulting trees were rooted using outgroup taxon. Tree visualization and drawing were carried out in TreeView version 1.5.2 (Page, 1996).

\section{RESULTS}

\section{Characteristics of colonies cultured on PDA}

The differences in growth speed in various Colletotrichum isolates were evident after 7 days of culture at $25^{\circ} \mathrm{C}$ (Figure 1). At this temperature, all isolates were clearly differentiated into two main types. The first type comprised the slow growing $C$. nymphaeae, C. incarnatum, and $C$. trichellum (the colonies were less than $5 \mathrm{~cm}$ in diameter). The other type included the fast growing $C$. circinans as well as the isolates of $C$. musae, $C$. dematium, $C$. capsici, $C$. caudatum, and C. caricae (the colonies were more than $5 \mathrm{~cm}$ in diameter).

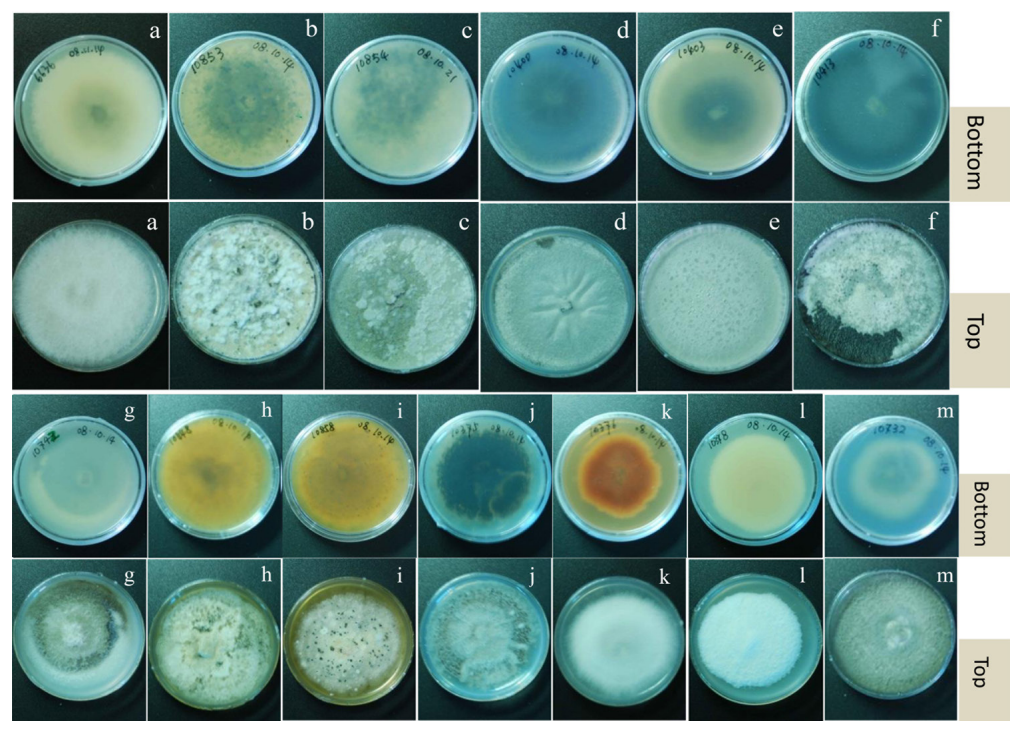

Figure 1. Colony characteristics of nine species of Colletotrichum cultured on PDA 7 days after inoculation. a.-c. C. musae; d.-f. C. dematium; g. C. caricae; h. C. caudatum; i. C. capsici; j. C. circinans; k. C. nymphaeae; l. C. trichellum; m. C. incarnatum.

Colony characteristics revealed a wide range of variation between different isolates even in the same species (Figure 1). All isolates could be separated into two groups. One group was characterized by upper side white, grey, and orange, cottony, and zonate and reverse side cream, yellow, or orange; some isolates were darker in the center $(6636 ; 10,655)$ or contained black spots $(10,858 ; 10,378)$. The other group was characterized by upper side olive-green, white, and gray, felty; reverse side cream, yellow-black, or gray-olive, mostly zonate, and darker in the center $(10,400 ; 10,403 ; 10,375 ; 10,372 ; 10,448)$ or having black spots $(10,853 ; 10,854 ; 10,732 ; 10,742)$. Morphological characters of the species are summarized in Table 3. 
Table 3. Morphological characters and GenBank accession Nos. of Colletotrichum isolates used in the study.

\begin{tabular}{|c|c|c|c|c|c|}
\hline \multirow[t]{2}{*}{ No. } & \multirow[t]{2}{*}{ Name } & \multirow[t]{2}{*}{ Morphologic characters } & \multicolumn{3}{|c|}{ GenBank accession No. } \\
\hline & & & $\beta$-tubulin & 28S rDNA & ITS \\
\hline 1 & C. musae & White, hairy, flat, superficial, reverse cream, darker at center, zonate & GQ369602 & GQ379688 & GQ369588 \\
\hline 2 & C. musae & $\begin{array}{l}\text { White, felty, powdery, fruiting bodies black with orange exudates, } \\
\text { reverse cream, darker at center }\end{array}$ & GQ369603 & GQ379699 & GQ369589 \\
\hline 3 & C. musae & $\begin{array}{l}\text { Grey, felty, powdery, fruiting bodies black with brown and orange } \\
\text { exudates, reverse cream }\end{array}$ & GQ369604 & GQ379700 & GQ369590 \\
\hline 4 & C. dematium & White, felty, hairy, superficial, radiate, reverse gray-olive & GQ369610 & GQ379693 & GQ369591 \\
\hline 5 & C. dematium & Grey, felty, reverse gray-olive & GQ369611 & GQ379695 & GQ369592 \\
\hline 6 & C. dematium & White, felty, reverse cream, darker at center & GQ369608 & GQ379692 & GQ369593 \\
\hline 7 & C. capsici & erse yellow with black spots & GQ369609 & GQ379701 & GQ369594 \\
\hline 8 & C. circinans & edge not smooth, reverse black & GQ369614 & 379690 & GQ369595 \\
\hline 9 & C. trichellum & White, cottony, thick, reverse cream & GQ369613 & GQ379691 & GQ369597 \\
\hline 10 & C. caudatum & Grey with black spot, felty, edge smooth, reverse yellow, darker at center & GQ369612 & GQ379694 & GQ369598 \\
\hline 11 & C. nymphaeae & White, cottony, reverse cream, zonate, darker at center & GQ369607 & GQ379697 & GQ369599 \\
\hline 12 & C. incarnatum & Grey, felty, superficial, reverse cream, zonate, darker at center & GQ369606 & GQ379689 & GQ369600 \\
\hline 13 & C. caricae & Grey with white, felty, superficial, reverse cream, zonate & GQ369605 & GQ379698 & GQ369601 \\
\hline
\end{tabular}

\section{Molecular data sets}

The data set of aligned $\beta$-tubulin sequences was 739 bp long, of which 363 (49.1\%) sites were variable and $198(26.8 \%)$ sites were parsimony informative. The aligned ITS sequences were 699 bp long, of which 294 (42.1\%) sites were variable and $63(9.0 \%)$ sites were parsimony informative. The average genetic (Tamura-Nei) distance within the in-group taxa was $44.1 \%$ for $\beta$-tubulin and $16.8 \%$ for ITS data sets. There was no excess of AT residues in $\beta$-tubulin (46.7\%) data set, whereas the genomic base composition was nearly balanced in the ITS $(47.8 \%)$ data set. The mean transition-to-transversion ratio (ti/tv ratio) was 1.09 and 1.29 for $\beta$-tubulin and ITS sequences, respectively.

In the 253-bp-long 28S rDNA data set, 17 (6.7\%) sites were variable and 11 (4.35\%) sites were parsimony-informative. The average genetic distance between in-group taxa was $3.2 \%$. The genomic base composition was slightly GC-rich $(40.7 \%)$ and the mean ti/tv ratio was 1.40 .

Table 4 shows sequence characteristics of the three datasets independently and combined. Comparison of the four data sets revealed that $\beta$-tubulin sequences had the largest proportions of variable and informative sites and higher Tamura-Nei distance (2.82-fold) than the other data sets. Sequences of the $28 \mathrm{~S}$ rDNA region showed the lowest percentage of variable and informative sites, although the mean ti/tv ratio was higher than in other two sequenced regions. In addition, the sequence divergence estimate was larger in ITS than in $28 \mathrm{~S}$ rDNA.

Table 4. Summary of statistics for each individual and combined phylogenetic datasets.
\begin{tabular}{lcccccc}
\hline Gene name & Variable site & Pi* & Total & AT \% & ti/tv* & Tamura-Nei \\
\hline$\beta$-tubulin & $363(49.1 \%)$ & $198(26.8 \%)$ & 739 & 46.7 & 1.09 & 0.441 \\
ITS & $294(42.1 \%)$ & $63(9.0 \%)$ & 699 & 47.8 & 1.29 & 0.168 \\
28 S rRNA & $17(6.7 \%)$ & $11(4.35 \%)$ & 253 & 40.7 & 1.40 & 0.032 \\
Combined & $674(39.9 \%)$ & $309(13.90 \%)$ & 1691 & 47.3 & 1.45 & 0.156 \\
\hline
\end{tabular}

$* \mathrm{Pi}=$ parisimony informative site; $\mathrm{ti} / \mathrm{tv}=$ mean transition-to-transversion ratio.

\section{Phylogenetic analysis}

The difference in the genetic base composition between the sequences of the three regions 
is reflected in the evolutionary models found to best fit each data set. Thus, the simple HKY and SYM models were chosen for the nearly balanced genetic base composition of $\beta$-tubulin and ITS data sets, whereas somewhat more complex GRT model was chosen for the 28S rDNA dataset.

The majority rule consensus tree from the combined Bayesian analyses is presented in Figure 2. From all trees generated from molecular data used three different analysis strategies. The MP, ML, and Bayesian analyses of the three dataset produced nearly identical tree topologies; they differed in bootstrap support (BS) values for some of the branches. The trees inferred from the combined dataset resolved $C$. capsici as the earliest diverging lineage followed by $C$. nymphaeae with high support (Bayesian posterior probability $[\mathrm{PP}]=1$; MP BS $=100 \%$; ML BS $=64 \%$ ). The remaining seven species formed two distinct clades. Clade 1 comprises two monophyletic clades; one includes $C$. circinans, $C$. trichellum, and C. caudatum, and the other three strains of $C$. dematium $(\mathrm{PP}=1 ; \mathrm{MP} \mathrm{BS}=93 \%$; ML BS $=85 \%)$. Clade 2 includes the basal $C$. incarnatum and a monophyletic clade comprised of three strains of C. musae and C. caricae (Figure 2).

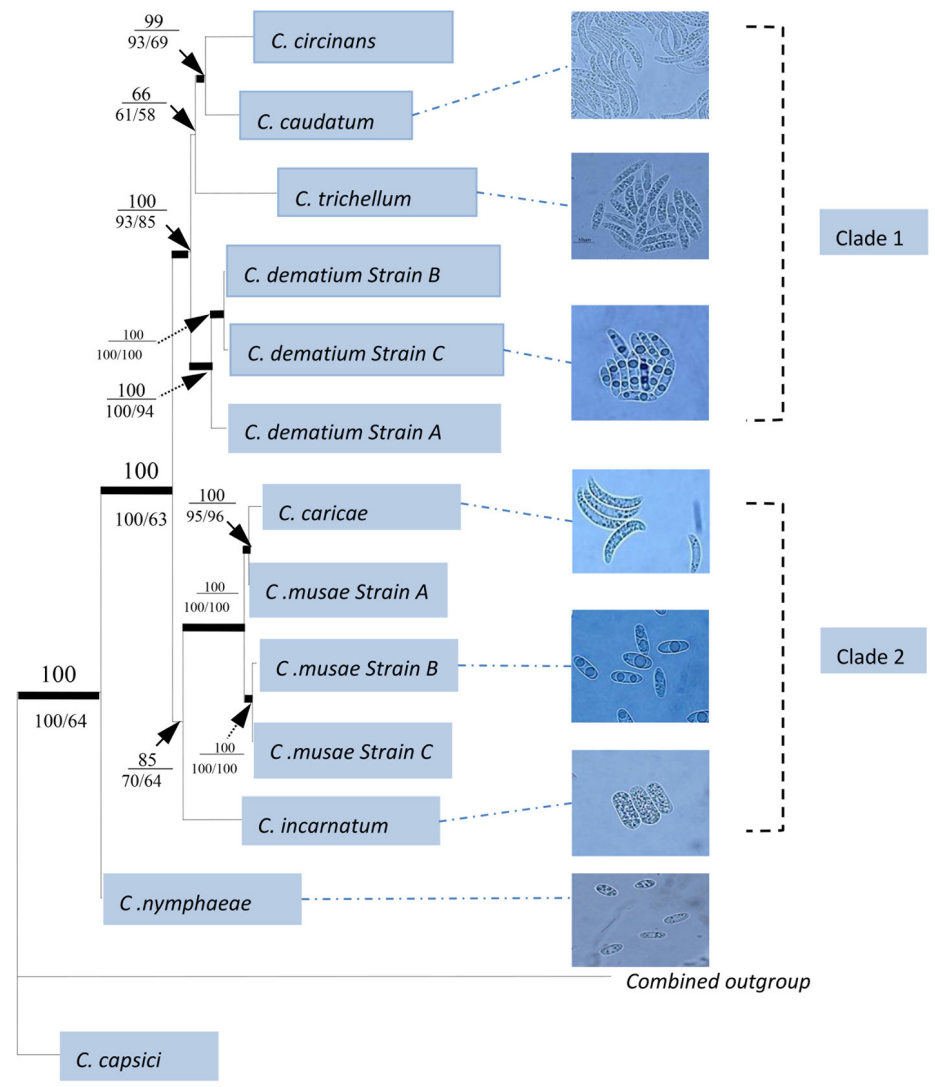

Figure 2. Majority-rule consensus tree resulting from the mixed-model Bayesian analysis of combined dataset $(1691 \mathrm{bp} ;$ model $=\mathrm{SYM}+\mathrm{G})$ illustrating the relationship between nine species of Colletotrichum; Physcia ainophila was used as outgroup. Branches represented with dashed lines were not recovered in the Bayesian consensus tree topology and are based on the maximum likelihood tree topology. Numbers above internodes indicate Bayesian posterior probabilities; numbers below internodes indicate non-parametric bootstrap proportions for parsimony analysis (left) and likelihood analysis (right). Thickened branches indicate Bayesian posterior probabilities $\geq 0.95$. The photos linked with species name by blue dotted lines represent the morphology of spores. 


\section{DISCUSSION}

\section{Which DNA sequence data is prior to phylogenetic analysis in the genus Colletotrichum?}

Forty four strains of Colletotrichum from various areas in Korea were divided into three genotypes, C. gloeosporioides, C. psidii, and C. acutatum, using different molecular markers. Among these markers, sequences of the protein coding gene $\beta$-tubulin have been used to differentiate strains and species of Colletotrichum (O'Donnell et al., 1998; Lee et al., 2007) and to carry out phylogenetic analyses of the C. acutatum species complex (Sreenivasaprasad and Talhinhas, 2005). Thus, apple and pepper strains of $C$. acutatum were resolved in two clades based on $\beta$-tubulin sequence data (Lee et al., 2007). The sequences of $\beta$-tubulin are 3.5 -fold more informative than mitochondrial small subunit ribosomal RNA sequences and therefore have been proposed as a suitable marker for studying close relationships in Fusarium (O'Donnell et al. 1998). In the present study, the phylogenetic relationships between nine species complexes of Colletotrichum were not clearly resolved by using $\beta$-tubulin sequence data although the sequences had the highest percentage (26.8\%) of parsimony-informative sites (Table 4$)$. The clade containing C. incarnatum and C. nymphaeae did not receive the same support in Bayesian and MP analyses and was unresolved in ML analysis. Furthermore, the positions of C. circinans and C. trichellum remained unresolved in the phylogenetic tree inferred from the $\beta$-tubulin dataset (Figure 3).

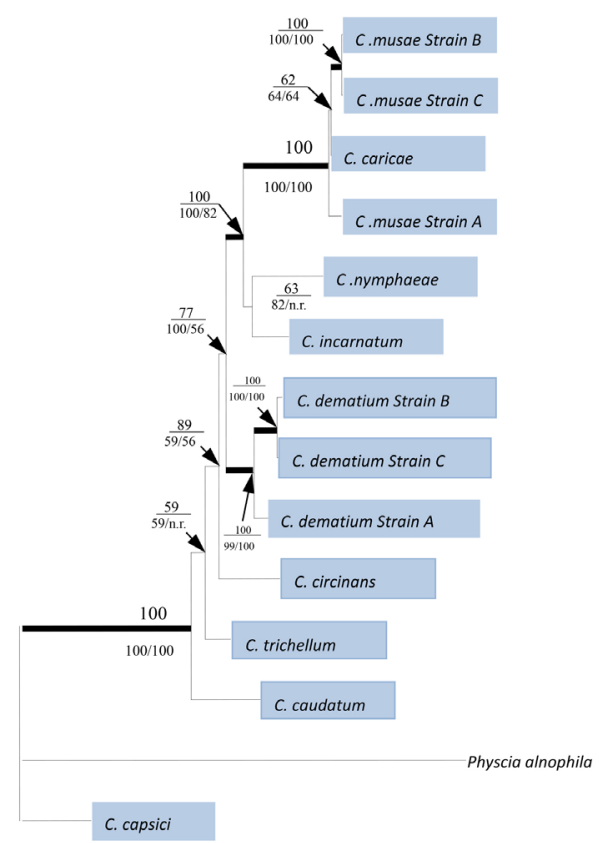

Figure 3. Majority-rule consensus tree resulting from Bayesian analysis of $\beta$-tubulin sequence data ( $739 \mathrm{bp}$; model $=\mathrm{HKY}+\mathrm{G})$ illustrating the relationship between nine species of Colletotrichum; Physcia ainophila was used as outgroup. Branches represented with dashed lines were not recovered in the Bayesian consensus and are based on the maximum likelihood tree topology. Numbers above internodes indicate Bayesian posterior probabilities; numbers below internodes indicate non-parametric bootstrap proportions for the parsimony analysis (left) and likelihood analysis (right). Nodes not recovered in one of the three analyses are indicated by "n.r.". Thickened branches indicate Bayesian posterior probabilities $\geq 0.95$. 
Several recent publications have reported on the use of rDNA sequence data in species delimitation in Colletotrichum (Sherriff et al., 1994; Crouch and Beirn, 2009). The analysis of sequence data from the D2 region of the large subunit rDNA resolved 16 distinct groups among the New Zealand fruit-rotting isolates including the accepted species $C$. coccodes, C. musae, C. orbiculare, C. acutatum, and C. gloeosporioides, which were separated into four broad groups, whereas the relationships of $C$. coccodes remained unresolved (Sherriff et al., 1994; Crouch and Beirn, 2009). The rDNA sequence data were unable to resolve the apparently stable morphological and cultural subgroups recognized within the sequenced groups (Johnston and Jones, 1997). However, Sherriff et al. (1994) showed that D2 region of the rDNA provided sufficient variation to discriminate between the groups of Colletotrichum defined by the combined D1 and D2 regions. In the present study, the relationship between three accessions of C. dematium, C. capsici, and C. caudatum remained unresolved, and the clade with $C$. circinans and $C$. trichellum was weakly supported in topologies based on the $28 \mathrm{~S}$ rDNA dataset. These results indicate that rDNA sequences alone are not suitable for phylogenetic studies in the genus Colletotrichum (Figure 4).

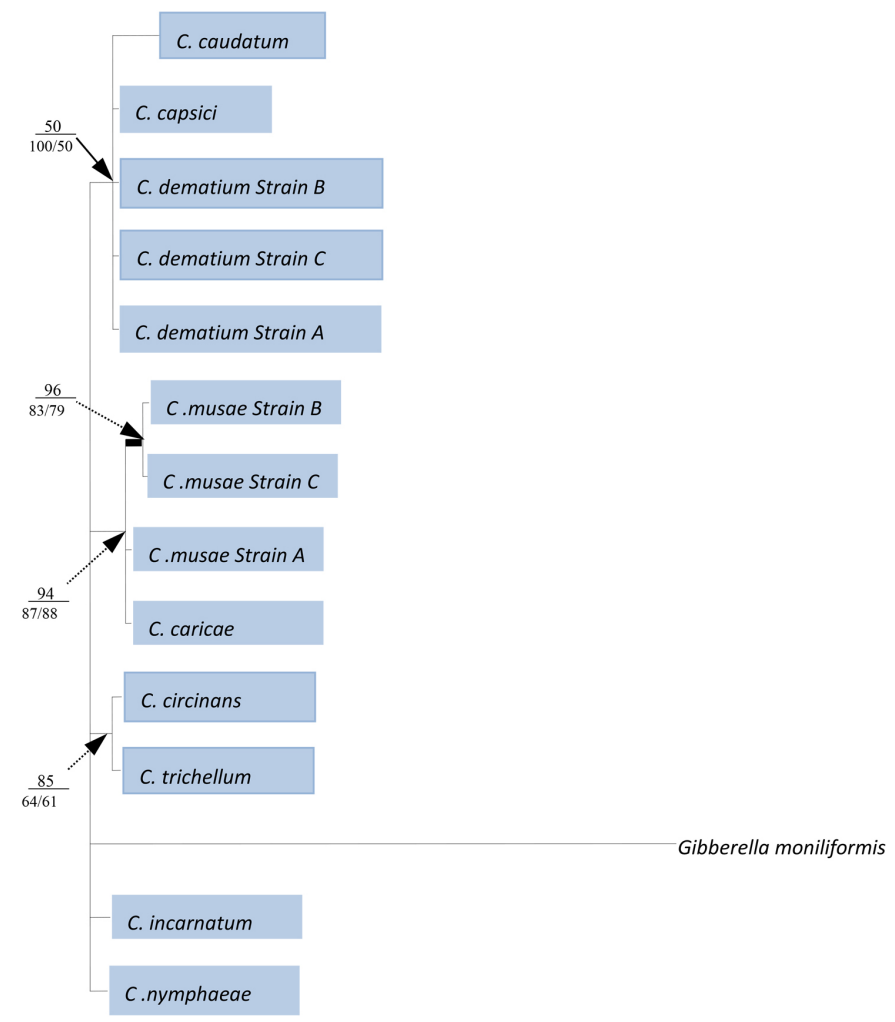

Figure 4. Majority-rule consensus tree resulting from Bayesian analysis of $28 \mathrm{~S}$ rDNA sequence data (253 bp; model $=\mathrm{GTR}+\mathrm{G})$ illustrating the relationships between nine species of Colletotrichum; Giberella moniliformis was used as outgroup. Branches represented with dashed lines were not recovered in the Bayesian consensus and are based on the maximum likelihood tree topology. Numbers above internodes indicate Bayesian posterior probabilities; numbers below internodes indicate non-parametric bootstrap proportions for the parsimony analysis (left) and likelihood analysis (right). Thickened branches indicate Bayesian posterior probabilities $\geq 0.95$. 
ITS sequence alone should not be used to infer evolutionary relationships in the genus Colletotrichum, nor should they be employed to describe novel Colletotrichum taxa. It is well established that the ITS sequences often generate poorly supported, unresolved phylogenetic trees in the genus, particularly when distant taxa are sampled (Crouch and Beirn, 2009). In the present study, in the phylogenetic tree inferred from the ITS sequence dataset, three strains of C. musae remained uresolved, whereas C. capsici and C. nymphaeae formed a monophyletic, strongly supported group (MP BS $=100 \%$ ), indicating that the latter two species exhibited high sequence identity in the ITS region. Furthermore, the support of many branches was below $70 \%$ and the topology was poorly resolved (Figure 5).

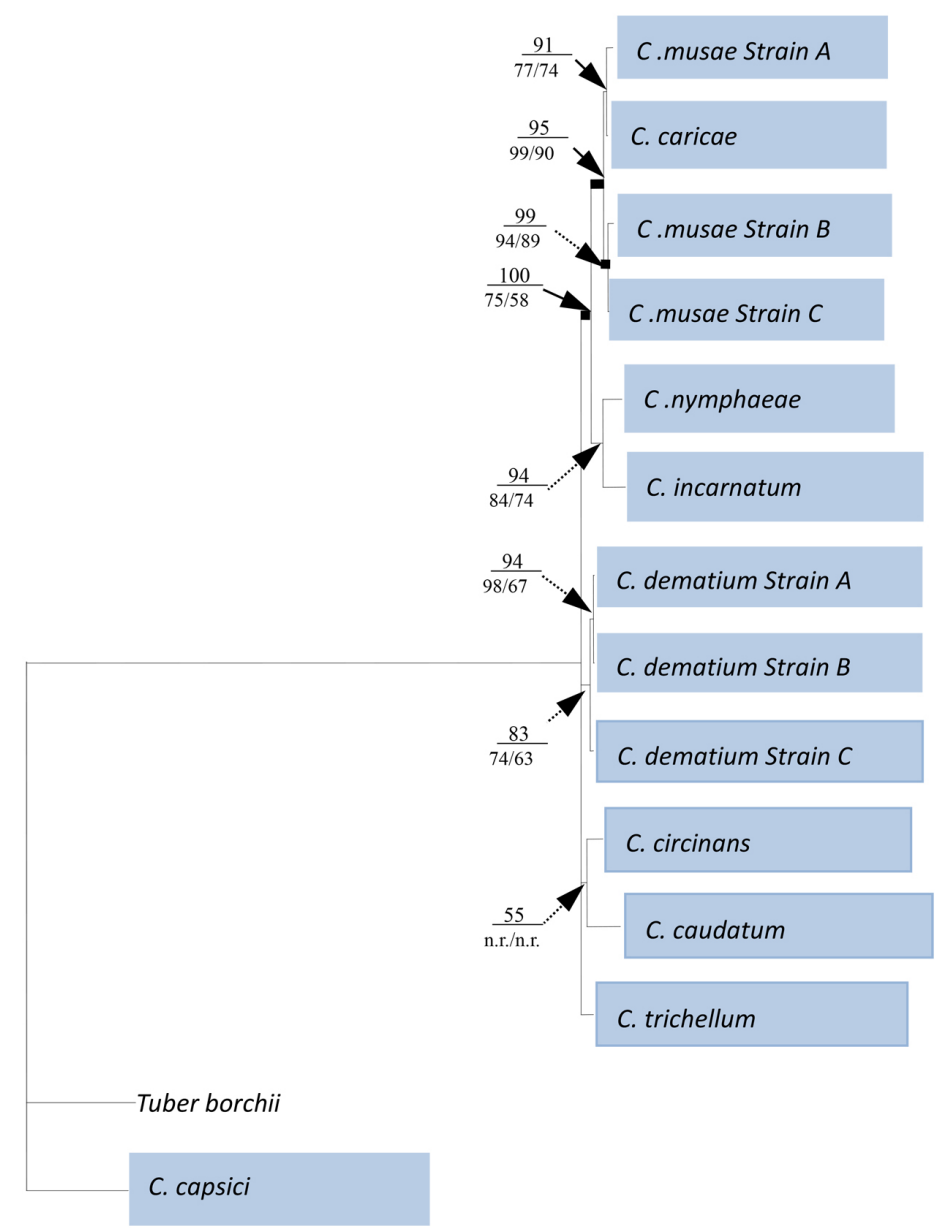

Figure 5. Majority-rule consensus tree resulting from Bayesian analysis of ITS sequence data $(699 \mathrm{bp}$; model = $\mathrm{K} 80+\mathrm{G}$ ) illustrating the relationship between nine species of Colletotrichum; Tuber borchii was used as outgroup. Branches represented with dashed lines were not recovered in the Bayesian consensus and are based on the maximum likelihood topology. Numbers above internodes indicate Bayesian posterior probabilities; numbers below internodes indicate non-parametric bootstrap proportions for the parsimony analysis (left) and likelihood analysis (right). Nodes not recovered in one of the three analyses are indicated by "n.r." Thickened branches indicate Bayesian posterior probabilities $\geq 0.95$. The species in blue are all sequenced successfully for the three regions. 
Similar to the topology inferred from $\beta$-tubulin and ITS sequences, the combined sequence data supported $C$. capsici as the most basal and thus the earliest diverging lineage. The clade containing $C$. circinans, $C$. caudatum, and $C$. trichellum was recovered in the Bayesian, ML, and MP analyses of the combined dataset, whereas this clade was not resolved in any of the topologies inferred from the single datasets. The bootstrap supports of each node in the phylogenetic trees were higher in Bayesian, MP, and ML analysis of the combined dataset (Figure 2). The results obtained herein suggest that the inter-species relationship of Colletotrichum are better resolved by the combined $\beta$-tubulin, ITS, and 28S rRNA sequence data than by the individual sequence dataset.

\section{Phylogeny}

C. capsici and C. dematium have often been confused because both species produce similar falcate conidia and are isolated from many types of plants (Moriwaki et al., 2002; Sutton, 1992). However, C. capsici and C. dematium are clearly divergent lineages as supported by the tree sequence datasets. $\beta$-Tubulin, ITS, and combined datasets highly supported the basal position of $C$. capsici in the tree topologies ( $\mathrm{PP}=1$; ML BS $=100 \%$; ML BS $=100 \%$ ), indicating that $C$. capsici is the most primitive member of the nine species of Colletotrichum.

$\beta$-tublin-, ITS-, and 28S rDNA- inferred tree topologies support the sister relationship of $C$. nymphaeae and $C$. incarnatum, while $C$. nymphaeae is sister to $C$. capsici in the phylogeny. In contrast, $C$. incarnatum was sister to $C$. musae albeit with low support in all tree topologies inferred from the combined datasets using the three algorithms $(\mathrm{PP}=0.85$; MP BS $=70 \%$; ML BS $=64 \%$ ), suggesting their close relationship (Figure 2$)$. The positions of the latter two species remain unresolved.

The analyses of the combined ITS and 28S rDNA D2 sequence data resolved $C$. circinans closely related to $C$. trichellum and both only distantly related to $C$. caudatum (Moriwaki et al., 2002). In the present study, C. circinans and C. trichellum formed a weakly supported clade based on $28 \mathrm{~S}$ rDNA sequence data, while $C$. circinans was resolved sister to $C$. caudatum in the ITS-inferred tree topology. The analyses of $\beta$-tubulin sequences did not resolve any of the two sister relationships, whereas in the topologies inferred from the combined dataset, $C$. circinans, $C$. trichellum, and C. caudatum formed a monophyletic clade, which was sister to the three populations of $C$. dematium with high support $(\mathrm{PP}=1$; $\mathrm{MP} \mathrm{BS}=$ $93 \%$; ML BS $=85 \%$ ).

In the phylogenetic trees based on combined sequence data, C. caricae and three strains of $C$. musae formed a clade that received high support ( $\mathrm{PP}=1$; MP BS $=100 \%$; ML $\mathrm{BS}=100 \%$ ), suggesting their close relationship. Among the three strains of C. musae, two of which originate from Mae Taeng, Thailand (Table 1) formed a clade, whereas strain A originating from Hongkong was sister to $C$. caricae in all tree topologies. The two species have a more derived position on the tree topologies inferred from $\beta$-tubulin and combined sequence data, indicating that they are the youngest members among the nine species.

The spore shape revealed some interesting trends in different species. Thus, the spores of C. acutatum isolated from Lupinus spp and other hosts had obtuse ends (in 0 to $28 \%$ of spores), one obtuse and one acute end (in 40 to $100 \%$ of spores) and acute ends (in 0 to $60 \%$ of spores), while the spores of C. gloeosporioides isolates have obtuse ends (in 68 to $100 \%$ of spores) (Talhinhas et al., 2002). The isolates (236) comprising 25 species of Colletotrichum in 
Japan were separated into three phylogenetic groups (PG): PG1 produces conidia with an acute end, PG2 produces conidia with an obtuse end, and PG3 of $C$. theae-sinensis has small conidia. The evolutionary trend of the conidial shape is toward small conidia, and from conidia with obtuse ends toward conidia with acute ends (Moriwaki et al., 2002).

In the present study, Colletotrichum species produced visible spores in multiple shapes, except $C$. circinans and $C$. capsici, these two species produced only one shape. Mass fusiform spores of $C$. dematium usually have both ends acute with one side curved (Figure 2), and conidia of $C$. caricae and $C$. caudatum are mostly falcate with acute ends. Ovoid conidia are always found in $C$. nymphaeae and $C$. incarnatum with obtuse ends, while fusiform spores of C. trichellum and C. musae have both ends acute but the conidia are not curved (Figure 2). Based on the phylogeny inferred from the combined dataset, the species with acute ends and curved conidia such as C. caricae, C. dematium, C. caudatum, and C. trichellum are mostly with the most divergent position in the phylogenetic tree, whereas the species with obtuse ends and straight conidia such as $C$. musae, $C$. nymphaeae, and $C$. incarnatum are resolved basal to the rest of the species and thus represent the primitive species of Colletotrichum. These results suggest that the evolutionary direction of the spore shape is from conidia with obtuse ends to conidia with acute ends and from straight to curved conidia. As for the spore size, there does not appear to be a clear evolutionary trend. Further analyses that will include additional species are necessary to confirm the evolutionary trends in the genus Colletotrichum.

\section{Conflicts of interest}

The authors declare no conflict of interest.

\section{ACKNOWLEDGMENTS}

The authors would like to thank Dr. Kevin D. Hyde for reviewing an earlier version of the manuscript. Also we express our gratitude to Dr. PoPo Than for donation of Colletotrichum isolates. Research supported by the Fundamental Research Funds for the Central Non-profit Research Institution (\#CAFYBB2014ZD005, \#riricaf2014001Z), the Introduction Project of International Advanced Technology of Forestry ("948" Program) (\#2014-4-66) and the Grant for Science and Technology Project of Yunnan Province (\#2013FB087).

\section{REFERENCES}

Bruns TD, White TJ and Taylor JW (1991). Fungal molecular systematics. Annu. Rev. Ecol. Syst. 22: 525-564.

Cai L, Hyde KD, Taylor PWJ, Weir BS, et al. (2009). A polyphasic approach for studying Colletotrichum. Fungal Divers. 39: 183-204.

Crouch JA and Beirn LA (2009). Anthracnose of cereals and grasses. Fungal Divers. 39: 19-44.

Faisal PM, Prema R, Nagendran K, Gandhi K, et al. (2013). A specific and sensitive method for the detection of Colletotrichum musae in banana fruit. Rev. Iberoam. Micol. pii: S1130-1406(13)00016-8. [Epub Ahead of Print].

Felsenstein J (1985). Confidence limits on phylogenies: an approach using the bootstrap. Evolution 39: 783-791.

Guerber JC, Liu B, Correll JC and Johnston PR (2003). Characterization of diversity in Colletotrichum acutatum sensu lato by sequence analysis of two gene introns, mtDNA and intron RFLPs, and mating compatibility. Mycologia 95: 872-895.

Hall TA (1999). BioEdit: a user-friendly biological sequence alignment editor and analysis program for Windows 95/98/ NT. Nucleic Acids Symp. Ser. 41: 95-98.

Hillis DM, Moritz C and Mable BK (1996). Molecular Systematic. 2nd edn. Sinauer Associates, Sunderland.

Huelsenbeck JP and Ronquist F (2001). MRBAYES: Bayesian inference of phylogenetic trees. Bioinformatics 17: 754-755. 
Hyde KD, Cai L, Cannon PF, Crouch JA, et al. (2009). Colletotrichum - names in current use. Fungal Divers. 39: 147-183. Johnston PR and Jones D (1997). Relationships among Colletotrichum isolates from fruit-rots assessed using rDNA sequences. Mycologia 89: 420-430.

Lee DH, Kim DH, Jeon YA, Uhm JY, et al. (2007). Molecular and cultural characterization of Colletotrichum spp. causing bitter rot of apples in Korea. Plant Pathol. J. 23: 37-44.

Manamgoda DS, Udayanga D, Cai L, Chukeatirote E, et al. (2013). Endophytic Colletotrichum from tropical grasses with a new species C. endophytica. Fungal Divers. 61: 107-115.

Moriwaki J, Tsukiboshi T and Sato T (2002). Grouping of Colletotrichum species in Japan based on rDNA sequences. J. Gen. Plant Pathol. 68: 307-320.

Moura HF, Vasconcelos IM, Souza CE, Silva FD, et al. (2014). Proteomics changes during the incompatible interaction between cowpea and Colletotrichum gloeosporioides (Penz.) Penz and Sacc. Plant Sci. 217-218: 158-175.

O’Donnell K, Cigelnik E and Nirenberg HI (1998). Molecular systematics and phylogeography of the Gibberella fujikuroi species complex. Mycologia 90: 465-493.

Page RDM (1996). TreeView: an application to display phylogenetic trees on personal computers. Comput. Appl. Biosci. 12: 357-358.

Peng LJ, Yang YL, Hyde KD, Bahkali AH, et al. (2012). Colletotrichum species on Citrus leaves in Guizhou and Yunnan provinces, China. Cryptogam. Mycol. 33: 267-283.

Peng LJ, Sun T, Yang YL, Cai L, et al. (2013). Colletotrichum species on grape in Guizhou and Yunnan provinces, China. Mycoscience 54: 29-41.

Peres NA, Mackenzie SJ, Peever TL and Timmer LW (2008). Postbloom fruit drop of citrus and key lime anthracnose are caused by distinct phylogenetic lineages of Colletotrichum acutatum. Phytopathology 98: 345-352.

Photita W, Taylor PWJ, Ford R, Hyde KD, et al. (2005) Morphological and molecular characterization of Colletotrichum species from herbaceous plants in Thailand. Fungal Divers. 18: 117-133.

Prihastuti H, Cai L, Crouch JA, Phoulivong S, et al. (2010). Neotypification of Colletotrichum falcatum, the causative agent of red-rot disease in sugarcane. Sydowia 62: 283-293.

Posada D and Crandall KA (1998). MODELTEST: testing the model of DNA substitution. Bioinformatics 14: 817-818.

Sherriff C, Whelan MJ, Arnold GM, Lafay JF, et al. (1994). Ribosomal DNA sequence analysis reveals new species groupings in the genus Colletotrichum. Exp. Mycol. 18: 121-138.

Smith BJ and Black LL (1990). Morphological, cultural, and pathogenic variation among Colletotrichum species isolated from strawberry. Plant Dis. 74: 69-76.

Sreenivasaprasad S and Talhinhas P (2005). Genotypic and phenotypic diversity in Colletotrichum acutatum, a cosmopolitan pathogen causing anthracnose on a wide range of hosts. Mol. Plant Pathol. 6: 361-378.

Sreenivasaprasad S, Mills PR and Brown AE (1994). Nucleotide sequence of the rDNA spacer 1 enables identification of isolates of Colletotrichum as C. acutatum. Mycol. Res. 98: 186-188.

Sreenivasaprasad S, Mills PR, Meehan BM and Brown AE (1996). Phylogeny and systematics of 18 Colletotrichum species based on ribosomal DNA spacer sequences. Genome 39: 499-512.

Sutton BC (1992). The genus Glomerella and its anamorph Colletotrichum. In: Colletotrichum biology, pathology and control (Bailey JA and Jeger MJ, eds.). CAB International, Wallingford, 1-26.

Swofford DL (2001). PAUP*: Phylogenetic analysis using parsimony (and other methods) 4.0b8. Sinauer Associates, Sunderland.

Talhinhas P, Sreenivasaprasad S, Neves-Martins J and Oliveira H (2002). Genetic and morphological characterization of Colletotrichum acutatum causing anthracnose of lupins. Phytopathology 92: 986-996.

Than PP, Jeewon R, Hyde KD, Pongsupasamit S, et al. (2008). Characterization and pathogenicity of Colletotrichum species associated with anthracnose on chilli (Capsicum spp.) in Thailand. Plant Pathol. 57: 562-572.

Thompson JD, Gibson TJ, Plewniak F, Jeanmougin F, et al. (1997). The Clustal_X windows interface: flexible strategies for multiple sequence alignment aided by quality analysis tools. Nucleic Acids Res. 25: 4876-4882.

von Arx JA (1957). Die Arten der Gattung Colletotrichum Cda. Phytopathol. Z. 29: 413-468.

Welsh J and McClelland M (1990). Fingerprinting genomes using PCR with arbitrary primers. Nucleic Acids Res. 18: 7213-7218.

Wharton PS and Diéguez-Uribeondo J (2004). The biology of Colletotrichum acutatum. An. Jard. Bot. Madr. 61: 3-22.

Wharton PS, Julian AM and O'Connell RJ (2001). Ultrastructure of the infection of Sorghum bicolor by Colletotrichum sublineolum. Phytopathology 91: 149-158.

White T, Bruns T, Lee S and Taylor J (1990). Amplification and direct sequencing of fungal ribosomal RNA genes for applications (Innis MA, Gelfand DH, Sninsky JJ and WhiteTJ eds.). Academic Press, New York.

Williams JGK, Kubelik AR, Livak KJ, Rafalski JA, et al. (1990). DNA polymorphisms amplified by arbitrary primers are 
useful as genetic markers. Nucleic Acids Res. 18: 6531-6535.

Wu HX, Schoch CL, Boonmee S, Bahkali AH, et al. (2011). A reappraisal of Microthyriaceae. Fungal Divers. 51: 189-248.

Wu HX, Li YM, Ariyawansa HA, Li WJ, et al. (2014). A new species of Microthyrium from Yunnan, China. Phytotaxa 176: 213-218. 